\title{
Assessment of muscle mass, risk of falls and fear of falling in elderly people with diabetic neuropathy
}

\author{
Avaliação da massa muscular, risco de quedas e medo \\ de cair em idosos com neuropatia diabética
}

\author{
Hudson Azevedo Pinheiro ${ }^{[a]}$, Karla Helena Coelho Vilaça ${ }^{[b]}$, Gustavo de Azevedo Carvalho ${ }^{[b] *}$ \\ [a] Centro Universitário Euroamericano (UNIEURO), Brasília, DF, Brazil \\ [b] Universidade Católica de Brasília (UCB), Brasília, DF, Brazil
}

\begin{abstract}
Objective: To assess muscle mass, risk of falls and fear of falling in elderly adults with diabetic neuropathy (DNP). Methods: 50 elderly patients with diabetes mellitus (DM) and diabetic neuropathy (NPD) participated in this study. Risk of falling was assessed using the Berg Balance Scale (BBS). Fear of falling was assessed by means of the Falls Efficacy Scale-International (FES-I). Muscle mass was assessed by tetrapolar bioimpedance analysis (BIA) and Janssen's equation. Subjects were divided into two groups: one with a history of falls in the six months before study enrollment (G1) and the other without history of falls (G2). Results: There were statistically significant differences between G1 and G2 regarding lean body mass ( $p<0.05)$, risk of falls as measured by the BBS $(\mathrm{p}<0.01)$, and fear of falling as measured by the FES-I $(\mathrm{p}<0.01)$. In addition, there was a significant correlation between the BBS and BIA $(r=0.45$ and $\mathrm{p}<0.01$ ), showing that the greater the lean body mass, the lower the risk of falling. Conclusions: We
\end{abstract}

* HAP: PhD, e-mail: hudsonap@gmail.com KHCV: PhD, e-mail: kavilaca@yahoo.com.br GAC: PhD, e-mail: carvalhobsb@hotmail.com 
found an association between lean mass, risk of falls and fear of falling in elderly adults with DNP and a history of falls from own height.

Keywords: Elderly. Diabetic Neuropathies. Sarcopenia. Accidents from falls. Fear.

\section{Resumo}

Objetivo: Avaliar a massa muscular, risco de quedas e medo de cair em idosos com neuropatia diabética (NPD). Métodos: Foram selecionados 50 pacientes idosos com diabetes mellitus (DM) e diagnóstico de neuropatia diabética (NPD) onde realizou-se avaliação do risco de queda pela escala de equilíbrio de Berg (EEB), medo de cair por meio da escala de eficácia de quedas (FES-I) e massa muscular por meio da bioimpedância tetrapolar (BIA) e equação de Jansen. Os indivíduos foram divididos em dois grupos: um com história de quedas nos últimos seis meses (G1) e sem história de quedas (G2). Resultados: Observou-se diferenças significativas entre G1 e G2 quanto à massa magra $(p, 0,05)$, risco de quedas por meio da EEB $(p<0,01)$ e medo de cair por meio da FES-I $(p<0,01)$, além de correlação importante entre a EEB e BIA( $r=0,45$ e $p<0,01)$, demonstrando que quanto maior for a massa magra, menor será o risco de cair. Conclusões: Houve associação entre pouca massa magra, risco e medo de cair em idosos com NPD no tocante a história de quedas da própria altura nessa população.

Palavras-chave: Idoso. Neuropatias Diabéticas. Sarcopenia. Acidentes por quedas. Medo.

\section{Introduction}

During the aging process, there is a progressive loss of lean body mass and an increase in the proportion of body fat. Among several age-related conditions, we may cite sarcopenia, which is characterized by a progressive and widespread loss of muscle mass, muscle strength and/or muscular performance. It leads to a poor health status, increased risk of falls and fractures, impaired functional capacity and increased risk of death. Thus, it has a negative (personal and financial) impact on society $(1,2,3)$.

Studies show that sarcopenia-related mechanisms lead to insulin resistance induced by inflammatory cytokines and to a state of fragility, and that elderly patients with diabetes mellitus (DM) are 1.5 to 2 times more likely to develop the frailty syndrome than elderly patients without DM $(4,5,6)$.

Neurological dysfunction is common people with diabetes and is usually associated with inadequate glycemic control. It can cause diabetic neuropathy (DNP), which is defined as "the presence of symptoms and/or signs of peripheral nerve dysfunction in people with diabetes after the exclusion of other causes". DNP leads to reduced tactile, thermal, vibratory and pain sensibility due to ischemic lesions of peripheral nerves $(7,8,9)$.
Neurological losses in the elderly may lead to the loss of protective sensibility to the plantar aspect of the foot - which is closely related to the establishment of ulcers -, as well as to muscle weakness and decreased range of motion (ROM), due to changes in the connective tissue component of the muscle and atrophy of intrinsic foot muscles. These culminate in changes in postural balance, since the feet are important proprioceptive tools that act dynamically to maintain balance and actively react against destabilization during functional activities such as gait (8-10).

Individuals with DNP have lower postural stability than non-diabetic subjects. Moreover, it is known, in association with this condition, aging itself leads to changes in compensatory mechanisms of postural balance. In addition, the increased risk of falls would be an indirect complication of diabetes mellitus, especially in diabetic patients who do not properly control their blood glucose levels $(11,12)$.

Thus, the aim of this study was to assess muscle mass, risk of falls and fear of falling in elderly adults with diabetic neuropathy (DNP).

\section{Methods}

This study was approved by the Research Ethics Committee of the Catholic University of Brasilia 
(UCB), protocol 46/2010. All participants received detailed information about the study objectives and procedures, and gave written informed consent (IC).

\section{Sample}

This was a cross-sectional study with a convenience sample of 50 inviduals. We analyzed the medical records of 250 patients seen at two public outpatient geriatrics clinics in the Federal District, Brazil, between January and June 2011. Only type 2 diabetic patients aged 60 years or older were selected for screening.

Individuals with type 1 diabetes mellitus, who were severely debilitated, bedridden or amputees, who had dementia, motor sequelae of stroke or plantar ulcers, or who were using assistive devices at study enrollment were excluded.

\section{Evaluation Procedures}

Data collection was conducted by the author through 1.5-hour single-session assessments, which took place at the Clinic of the School of Physical Therapy of UCB, during the month of July 2011.

The presence of NP was established using the Neuropathy Symptom Score (NSS)- which consists of a questionnaire on neuropathic symptoms, such as complaints of burning and tingling in the feet, and factors that relieve or worsen such symptoms - and the Neuropathy Disability Score (NDS) - which consists of neurological tests on both feet: Achilles Reflex, vibratory sensitivity using a tuning-fork, and tactile and pain sensitivity. These instruments have been validated for the Brazilian population by Moreira et al. and show good reliability and reproducibility for diagnosing DNP (13).

Body composition was measured by Bioelectrical Impedance Analysis (BIA) using a four-pole device (Byodinamics ${ }^{\circledR}$ Model 310). Measurements were performed with the patient placed on a stretcher in supine position, barefoot, legs apart, feet placed $30 \mathrm{~cm}$ apart and with the arms parallel to the body. Patients rested for at least 10 minutes before the measurements were taken and were instructed to discontinue the use of diuretics at least nine hours prior to the test. They were also asked to take off all metallic objects they were wearing and avoid the consumption of food and beverages up to four hours before the test. These guidelines are given in the study protocol by Convenient et al. (14).

Lean body mass and sarcopenia were determined by using the equation proposed by Janssen et al. (specified below). Age at the time of interview is reported as age in years at the last birthday. A score of 1 was used for males and a score of zero was used for females (2).

$$
\begin{aligned}
& \text { LEAN BODY MASS }(\text { KG })=[(S Q U A R E D \text { HEIGHT / } \\
& \text { BIOELECTRICAL RESISTANCE } \times 0.401)+(\text { SEX } \times \\
& 3.825)+(\text { AGE } \times-0.071)]+5.102
\end{aligned}
$$

The risk of falls was determined using the Berg Balance Scale (15), which consists of 14 tasks involving static and dynamic balance control during the performance of functional tasks and ranges from 0 to 56. Each task has five alternatives and an ordinal scale from 0-4. Zero indicates that the individual was not able to perform the task and 4 indicates that the subject was able to accomplish the task without any problems. The BBS has been validated for the Brazilian population with 0.98 sensitivity and 0.99 specificity. A score equal to or higher than 45 indicates risk of fall. In this study we used the cut-off point proposed by Berg et al. (16).

The Falls Efficacy Scale-International (FES-I) is a self-administered questionnaire that measures the fear of falling in elderly people. The FES-I has been translated and validated for the Brazilian population by Camargos et al., who reported that a score $\geq 23$ suggests an association with a history of sporadic fall, whereas a score $\geq 31$ entails an association with recurrent falls (17). The entire assessment protocol was conducted by the researchers of this study.

\section{Statistical Analysis}

Statistical analysis was performed using SSP version 20 for Windows. First, descriptive statistics (mean and standard deviation) was use to analyze the data. The Kolmogorov-Smirnov test was used for checking the normality of data distribution.

BBS, FES-I and lean body mass values of G1 and G2 were compared using the Student's t test. The probability of type I error was set at 5\% for all tests $(p<0.05)$. We also analyzed the relationship between sarcopenia and BBS using Pearson's correlation test $(\mathrm{p}<0.05)$. 


\section{Results}

50 elderly patients met the inclusion and exclusion criteria and were included in this study. All participants were diagnosed with DNP according to the NSS and NDS, and were divided into two groups: one with a history of falls in the six months before study enrollment (G1) and the other without history of falls (G2).

G1 was composed of 24 individuals (of which 20 were female) with a mean age of $67.8 \pm 7.0$ years. G2 was composed of 26 individuals (of which 21 were female) with a mean age of $65.5 \pm 4.9$ years. The mean time since diagnosis of diabetes mellitus was $15.7 \pm$ 9.1 years in both groups.

Table 1 shows the relationship between G1 and G2 regarding functional (BBS, FES-I) and body composition variables. There were statistically significant differences in lean body mass and BBS ( $p<0.01)$ between both groups.

Figure 1 shows the relationship between BBS and lean mass as measured by BIA. There was statistical significance $(\mathrm{p}<0.01)$ and a moderate positive correlation $(r=0.45)$ between the scores of the two measures.

Table 1 - Comparison of functional and body composition variables between Gl and G2

\begin{tabular}{lccc}
\hline & G1 & G2 & P \\
& N = 24 & N = 26 & \\
\hline BBS (score range of 0-56) & $44.75 \pm 6.51$ & $52.00 \pm 2.97$ & $\mathbf{0 . 0 0 1}$ \\
\hline FES-I (score range of 0-64) & $31.58 \pm 8.20$ & $25.00 \pm 7.10$ & $\mathbf{0 . 0 0 1}$ \\
\hline Lean body mass (Kg) & $17.27 \pm 2.25$ & $19.00 \pm 3.24$ & $\mathbf{0 . 0 3}$ \\
\hline
\end{tabular}

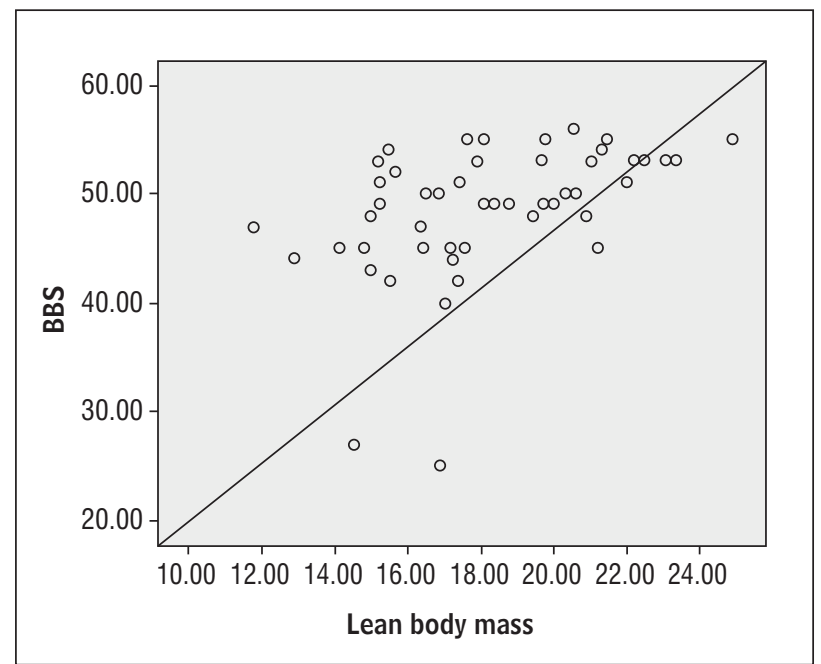

Figure 1 - Correlation between BBS and lean body mass in relation to the risk of falls in elderly patients with DNP

Note: $r=0.45 ; p=0.001$.

\section{Discussion}

Our results showed a correlation between the BBS scores and the amount of lean body mass in the sample of elderly patients with DNP. In addition, we found that the group of patients with a history of falls had higher scores on the BBS and FES-I, and lower muscle mass compared to the group without history of falls.

This finding leads us to infer that the lower the muscle mass index and the scores on the BBS, the greater the risk of falls in elderly patients with DNP. This is in line with the study conducted by Bretan et al. with 45 elderly patients with type 2 diabetes. In their study, the authors have correlated mean BBS scores and plantar sensitivity as determined with 10-g monofilament, and found mean BBS scores of $48.89 \pm 3.51$. In addition, according to their results, only four elderly patients (9\%) showed changes in skin sensitivity (18).

This study showed a significant correlation between BBS and FES-I scores, indicating that the greater the risk of falling, the greater the fear of falling. This finding has been also reported by Custodio et al. in their study correlating risk of falls and fear of falling with executive functions such as memory and information processing in elderly adults with low education. The authors also state that the better the resolution in which the environment is visually perceived, the better the postural strategies 
used for balance control and the smaller the fear of falling (19).

Pinheiro et al. have found that $67 \%$ of falls in older adults with DNP occur outdoors, be it in the backyard or even in the street. The authors also report that a single fall event negatively affects the life of elderly individuals by generating insecurity regarding leaving home (due to the fear of falling again). This fear of leaving home may well lead to a greater risk of death and could contribute to increased depression, ptophobia and dependency to perform activities of daily living (ADL) (20). This finding corroborates the results of this study, in which the mean scores obtained in the FES-I show that both groups (G1 and G2) have a significant fear of falling.

Cordeiro et al. have used the BBS in elderly outpatients with diabetes mellitus and found that they had (mainy age-related) impaired balance and mobility, ADL limitation, no balance strategy, impaired proprioceptive sensitivity and postural hypotension (21).

In their study, Lopes et al. have reported that approximately $20-60 \%$ of the elderly experienced fear of falling, and that this fear is often higher among women, especially when they have sedentary lifestyles (22).

These findings are in line with this study, in which the study population also consisted of communitydwelling elderly people, mostly women (in both groups), who had fear of falling - despite the fact that subjects in G2 had never experienced a fall.

The fear of falling has negative effects on the physical and functional well-being of the elderly. It leads to a higher dependence and a decreased ability to perform ADL and socialization tasks. It contributes to physical inactivity, which in turn leads to sarcopenia, loss of balance, gait abnormalities and increased risk for falls. In addition, it strongly influences the concepts of self-efficacy, which are intrinsically associated not only with physical improvement, but also with psychosocial aspects $(16,23,24)$.

In their review study on the fear of falling in elderly persons, Macedo et al. have found that, when asked to walk around, those elderly who had a history of falls reported feeling fear and anxiety, and tended to grab objects for support and stumble forward as if a fall was imminent. They used especially lighttouch strategies (use of hands) because many did not trust or feel safe using more physiological and automatic strategies, which usually involve the use of the legs (25).
With regard to the body composition and lean body mass as measured by Janssen's equation, we found that none of the subjects had sarcopenia. However, there were significant differences between G1 and G2. Those patients who had less lean body mass were at a higher risk of falling, a fact demonstrated by the correlation between BBS scores and lean body mass values (2).

The studies by Kim et al. and van Sloten et al. also report on the deleterious effects of DM on the health of elderly persons. According to these authors, it leads to physical changes such as sarcopenia and obesity which are directly associated with loss of functional capacity and increased risk of falls -, as well as to psychosocial problems such as depression and fear of falling, especially in patients with $\operatorname{DNP}(26,27)$. These findings were also observed in this study. We found that the group of patients with a history of falls had lower muscle mass and higher scores on the BBS and FES-I compared to the group without history of falls. In this study, muscle strength in the lower limbs and the degree of muscle atrophy (especially in intrinsic muscles of the feet) was not taken into account. This could explain the association between lower lean body mass and increased risk of falls, which was observed in this study.

The literature reports that loss of both muscle mass and muscle strength occurs throughout the life cycle, and that changes in muscle mass are accompanied by proportional increments in strength (28).

In a cohort study, Tilling et al. have found that elderly patients with diabetes are at high risk of falls, especially those patients with inadequate glycemic control. According to the authors, strategies to minimize such risk include: instructing the patient about the disease, and about specific strength- and balancetraining exercise programs (12). Schwartz et al. have also reported a direct relationship between control of blood sugar level and risk of falls, and stated that, in order to minimize the risk of falling, it is essential that patients control their blood sugar levels (29).

DNP is cited in the literature as being the main complication of diabetes mellitus and significantly affecting the quality of life of patients in terms of mobility and postural balance (30). Similar findings were also observed in this study, since the elderly patients with DNP showed changes in muscle mass, which may interfere with postural stability and increase the risk of falling. 
In this study we did not evaluate whether glycemic control influenced postural stability, risk of falling or fear of falling. We suggest that this variable be considered in future studies.

\section{Conclusion}

Elderly people with diabetic neuropathy and history of falls in the previous six months have lower muscle mass, are at greater risk of falls and have greater fear of falling.

\section{References}

1. Cruz-Jentoft AJ, et al. Sarcopenia: European consensus on definition and diagnosis. Age and Ageing. 2010; 39:412-23.

2. Janssen I, et al. Skeletal muscle cutpoints associated with elevated physical disability risk in older men and women. Am J Epidemiol. 2004;159:413-21.

3. Muscaritoli M, et al. Consensus definition of sarcopenia, cachexia and pre-cachexia: Joint document elaborated by Special Interest Groups (SIG) cachexiaanorexia in chronic wasting diseases and nutrition in geriatrics. Clin Nutr. 2010;29(2):154-9.

4. Khamseh ME, et al. Sarcopenia and diabetes: pathogenesis and consequences. British J Diabetes \& Vasc Disease. 2011;11(5):230-4.

5. Morley JE. Diabetes, sarcopenia, and frailty. Clin Geriatr Med. 2008;24:455-69.

6. Pierine DT, Nicola M, Oliveira EP. Sarcopenia: alterações metabólicas e consequências no envelhecimento. R bras Ci e Mov. 2009;17(3):96-103.

7. Gagliardi ART. Neuropatia diabética periférica. J Vasc Br. 2003;2(1):67-74.

8. Sacco ICN et al. Avaliação das perdas sensório-motoras do pé e tornozelo decorrentes da neuropatia diabética. Rev. Bras. Fisioter. 2007;11(1):27-33.

9. Schmid H, Neumann C, Brugnara L. O diabetes melito e a desnervação dos membros inferiores: a visão do diabetólogo. J Vasc Br. 2003; 2(1):37-48.
10. Camargo MR, Fregonesi CEPT. A importância das informações aferentes podais para o controle postural. Rev Neurocienc. 2011;19(1):165-70.

11. Oppenhein $U$, et al. Postural characteristics of diabetic neuropathy. Diabetes Care. 1999;22(2):328-33.

12. Tilling LM, Darawil K, Britton M. Falls as a complication of diabetes mellitus in older people. J Diab Comp. 2006;20:158-62.

13. Moreira R, et al. Tradução para o português e avaliação da confiabilidade de uma escala para diagnóstico da polineuropatia distal diabética. Arq Bras Endocrinol Metab. 2005;49(6):944-50.

14. Cômodo ARO, et al. Utilização da bioimpedância para avaliação da massa corpórea. [Cited in 2011 Mar 22]. Available from: http://tinyurl.com/q5vv2ll.

15. Miyamoto ST, et al. Brazilian version of the Berg balance scale. Braz J Med Biol Res. 2004;37:1411-21.

16. Berg KO, Wood-Dauphinee SL, Williams JI, Maki BE. Measuring balance in the elderly: validation of an instrument. Can J Public Health. 1992;83(suppl2): S7-S11.

17. Camargos FFO, Dias RC, Dias JMD, Freire MTF. Adaptação transcultural e avaliação das propriedades psicométricas da Falls Efficacy Scale - International em idosos brasileiros (FES-I-BRASIL). Rev Bras Fisioter. 2010;14(3):237-43.

18. Bretan O, Pinheiro RM, Corrente JE. Avaliação funcional do equilíbrio e da sensibilidade cutânea plantar de idosos moradores na comunidade. Braz J Otorhinolaryngol. 2010;76(2):219-24.

19. Custódio EB, Malaquias JR, Voos MC. Relação entre cognição (função executiva e percepção espacial) e equilíbrio de idosos de baixa escolaridade. Fisioter Pesq. 2010;17(1):46-51.

20. Pinheiro HA, et al. Ptofobia, depressão e história de quedas em idosos com neuropatia diabética do Distrito Federal. Rev Kairos Geront. 2013;15(5):45-56.

21. Cordeiro RC, et al. Factors associated with functional balance and mobility among elderly diabetic outpatients. Arq Bras Endocrinol Metab. 2009;53(7):834-43.

22. Lopes KT, et al. Prevalência do medo de cair em uma população de idosos da comunidade e sua correlação com mobilidade, equilíbrio dinâmico, risco e historio de quedas. Rev Bras Fisioter. 2009;13(3):223-9. 
23. Pinheiro HA, Loureiro AML. Análise dos aspectos gerontológicos na canção Filho Adotivo. Rev. Bras. Geriat. Gerontol. 2011;5(2):99-105.

24. Rezende $\mathrm{AAB}$, et al. Medo do idoso em sofrer quedas recorrentes: a marcha como fator determinante da independência funcional. Acta Fisiatr. 2010; 17(3): 117-21.

25. Macedo BG, et al. Parâmetros clínicos para identificar o medo de cair em idosos. Fisioter em Movimento. 2005;18(3):65-70.

26. Kim TN, et al. Prevalence and determinant factors of sarcopenia in patients with type 2 diabetes. Diabetes Care. 2010;33(7):1497-9.

27. Van Sloten TT, et al. Peripheral neuropathy, decrease muscle strengh and obesity are strongly associated with walking in persons with type 2 diabetes without manifest mobility limitations. Diabetes Res Clini Pract. 2011;91:32-9.
28. Ferrucci L, de Cabo R, Knuth ND, Studenski S. Of Greek heroes, wiggling worms, mighty mice, and old body builders. J Gerontol A Biol Sci Med Sci. 2012; 67A(1):13-6.

29. Schwartz AV, et al. Older women with diabetes have a higher risk of falls. Diabetes Care. 2002; 25(10): 1749-54.

30. Brod M, et al. Burden of illness of diabetic peripheral neuropathic pain: a qualitative study. The patientpatient-centered outcomes research. 2014; 1-10

Received: $11 / 14 / 2013$

Recebido: 14/11/2013

Approved: 05/12/2015

Aprovado: 12/05/2015 
